\title{
Health effects of vegetarian and vegan diets
}

\author{
Timothy J. Key*, Paul N. Appleby and Magdalena S. Rosell \\ Cancer Research UK Epidemiology Unit, University of Oxford, Richard Doll Building, Roosevelt Drive, \\ Oxford OX3 $7 L F, U K$
}

\begin{abstract}
Vegetarian diets do not contain meat, poultry or fish; vegan diets further exclude dairy products and eggs. Vegetarian and vegan diets can vary widely, but the empirical evidence largely relates to the nutritional content and health effects of the average diet of well-educated vegetarians living in Western countries, together with some information on vegetarians in nonWestern countries. In general, vegetarian diets provide relatively large amounts of cereals, pulses, nuts, fruits and vegetables. In terms of nutrients, vegetarian diets are usually rich in carbohydrates, $n-6$ fatty acids, dietary fibre, carotenoids, folic acid, vitamin C, vitamin E and $\mathrm{Mg}$, and relatively low in protein, saturated fat, long-chain $n-3$ fatty acids, retinol, vitamin $\mathrm{B}_{12}$ and $\mathrm{Zn}$; vegans may have particularly low intakes of vitamin $\mathrm{B}_{12}$ and low intakes of $\mathrm{Ca}$. Crosssectional studies of vegetarians and vegans have shown that on average they have a relatively low BMI and a low plasma cholesterol concentration; recent studies have also shown higher plasma homocysteine concentrations than in non-vegetarians. Cohort studies of vegetarians have shown a moderate reduction in mortality from IHD but little difference in other major causes of death or all-cause mortality in comparison with health-conscious non-vegetarians from the same population. Studies of cancer have not shown clear differences in cancer rates between vegetarians and non-vegetarians. More data are needed, particularly on the health of vegans and on the possible impacts on health of low intakes of long-chain $n$ - 3 fatty acids and vitamin $B_{12}$. Overall, the data suggest that the health of Western vegetarians is good and similar to that of comparable non-vegetarians.
\end{abstract}

Vegetarian: Vegan: Health: Mortality

A large number of individuals around the world follow vegetarian diets, but in most countries vegetarians comprise only a small proportion of the population. India is a notable exception because a substantial proportion of the population, perhaps approximately $35 \%$, follows a traditional vegetarian diet and has done so for many generations (International Vegetarian Union, 2005; Refsum et al. 2001). The numbers of vegetarians in Western countries are unknown, with estimates based on rather small samples; for example, in a survey of 2251 individuals throughout the UK (Henderson et al. 2002) $5 \%$ reported being vegetarian or vegan. While the number of vegetarians may be increasing in some of the most affluent countries, there is an opposite picture for other countries around the world, in that meat consumption is increasing greatly in many countries that until recently had a low intake of meat. Per capita meat consumption ( $\mathrm{kg} / \mathrm{year})$ is predicted to increase from $24 \cdot 2$ in $1964-6$ to $45 \cdot 3$ in 2030 , with a very large increase in East Asia from only 8.7 in 1964-6 to $58 \cdot 5$ in 2030 (World Health Organization, 2003). Steinfeld (2004) has estimated that world total meat production $\left(\times 10^{6}\right.$ tonnes/year) increased from about 92 in 1967-9 to 218 in 1997-9 and will increase further to 376 in 2030, a fourfold increase in 60 years.

Understanding of the health effects of vegetarian and vegan diets is quite good but many uncertainties remain (Fraser, 1999; Key et al. 1999a; Sanders, 1999a; Willett, 2003). The purpose of the present brief overview is to summarize current knowledge on the health effects of vegetarian and vegan diets with an emphasis on recent findings and results from large studies, including the work of the authors' group on the European Prospective Investigation of Cancer and Nutrition (EPIC)-Oxford cohort (Davey et al. 2003). Most of the discussion is related to vegetarians in affluent Western countries; the health of vegetarians and individuals with a very low meat intake in

\footnotetext{
Abbreviation: EPIC, European Prospective Investigation of Cancer and Nutrition.

*Corresponding author: Professor Tim Key, fax +44 1865289610 , email tim.key@ceu.ox.ac.uk
} 
poorer countries is a very important topic and there is some information available, but proper consideration of this topic is outside the scope of the present brief overview.

\section{Dietary characteristics of vegetarian diets}

Vegetarians are defined as individuals who do not eat any meat, poultry or fish. Vegetarians are sub-classified as lacto-ovo vegetarians who eat dairy products and/or eggs and vegans who do not eat any animal products. Since vegetarian diets are defined by what they do not contain, the actual composition of vegetarian diets can vary widely. For the purpose of the present review the discussion is largely based on the observed average diet of vegetarians as described in published reports, and mostly for individuals living in affluent Western countries.

\section{Nutritional status of vegetarians \\ Nutrient intake}

Reviews by expert groups such as the American Dietetic Association and Dietitians of Canada (2003) have concluded that a well-planned vegetarian diet is adequate for all stages of the life cycle including infancy, childhood and adolescence. Comparisons of the food intakes of vegetarians and non-vegetarians show that vegetarian diets generally provide relatively large amounts of cereals, pulses, nuts, fruits and vegetables. Together with the differences in intakes of animal foods, these differences in food intake result in several characteristic differences in nutrient intake. Vegetarian diets are usually rich in carbohydrates, n-6 fatty acids, dietary fibre, carotenoids, folic acid, vitamin $\mathrm{C}$, vitamin $\mathrm{E}$ and $\mathrm{Mg}$, and relatively low in protein, saturated fat, long-chain $n-3$ fatty acids, retinol, vitamin $\mathrm{B}_{12}$ and $\mathrm{Zn}$; vegans can have particularly low intakes of vitamin $\mathrm{B}_{12}$ and low intakes of $\mathrm{Ca}$ (e.g. data from EPICOxford; Davey et al. 2003).

These differences in nutrient intake might have favourable or unfavourable effects on the nutritional status and health of vegetarians. Current knowledge of nutrition suggests that the relatively high intakes of dietary fibre, folic acid, vitamin $\mathrm{C}$, vitamin $\mathrm{E}$ and $\mathrm{Mg}$ and low intake of saturated fat might all have benefits. In particular, vegetarians are more likely than non-vegetarians to reach the UK Department of Health (1991) targets for fruit and vegetables and the dietary reference values for saturated fatty acids of $10 \%$ total energy and NSP of $18 \mathrm{~g} / \mathrm{d}$. For example, mean saturated fat intakes expressed as percentage energy are estimated as 10.7 and 10.4 in male and female meat-eaters, 9.4 and 9.3 in male and female vegetarians and $5 \cdot 0$ and $5 \cdot 1$ in male and female vegans (Davey et al. 2003). For NSP, mean intakes (g/d) are 18.7 and 18.9 in male and female meat-eaters, 22.7 and 21.8 in male and female vegetarians, and 27.7 and 26.4 in male and female vegans (Davey et al. 2003).

The impact on health of the relatively high intakes of carbohydrates and n-6 fatty acids and relatively low intakes of protein, retinol and $\mathrm{Zn}$ in vegetarians is unclear; mean intakes of these nutrients in vegetarians are probably close to or above the recommended intakes, where applicable (Davey et al. 2003), and these nutrients are not discussed further in the present review. For $n-3$ fatty acids and vitamin $\mathrm{B}_{12}$, however, there is substantial recent research relevant to the status of vegetarians in relation to these nutrients and this aspect will be discussed further, together with Fe status.

\section{n-3 Fatty acids}

Plant foods can provide $\alpha$-linolenic acid but are devoid of the long-chain $n-3$ fatty acids EPA and DHA (marine algae can provide EPA and DHA and are acceptable to vegetarians but are not considered here as a plant food); eggs and to a lesser extent dairy products contain low levels of EPA and DHA that vary according to the feeding of the animal. Studies of plasma levels of $n-3$ fatty acids have consistently shown that vegetarians have lower levels of EPA and DHA than meat-eaters, with lower levels in vegans than in lacto-ovo-vegetarians (Sanders et al. 1978a; Sanders, 1999b). Recently, it has been shown that plasma levels of EPA and DHA in vegans are not related to the duration of adherence to the diet over periods of $\leq 20$ years, suggesting that the endogenous production of these fatty acids in vegetarians and vegans may result in low but stable plasma concentrations (Rosell et al. 2005c). Studies using labelled $\alpha$-linolenic acid have shown that conversion of this fatty acid to EPA and DHA can occur in human subjects but that the rate of conversion is low in females and very low in males (Williams \& Burdge, 2006). Vegetarian diets are usually rich in linoleic acid, which may reduce the conversion of $\alpha$-linolenic acid to EPA and DHA (Davis \& Kris-Etherton, 2003), but there is no direct evidence that plasma levels of EPA and DHA in vegetarians can be substantially increased by following a diet low in linoleic acid and high in $\alpha$-linolenic acid.

It is unknown whether the low levels of EPA and DHA in the plasma of vegetarians have effects on health. In a small uncontrolled trial in which supplements of EPA and DHA were given to ten vegetarians Mezzano et al. (2000) observed an increase in the plasma levels of these fatty acids and a reduction in platelet aggregation, a possible risk factor for CVD, but more research is needed to explore this possible effect.

\section{Vitamin $B_{12}$}

Food plants do not contain vitamin $\mathrm{B}_{12}$; therefore, the only reliable sources of vitamin $B_{12}$ for vegetarians are dairy products and eggs, fortified foods and dietary supplements (Herbert, 1988; Dagnelie et al. 1991). It has been claimed that some plant foods such as seaweed and tempeh might provide true vitamin $\mathrm{B}_{12}$, but this claim has not been established and much or all the material in these foods that is detected by assays for vitamin $\mathrm{B}_{12}$ may be vitamin $\mathrm{B}_{12}$ analogues that are either inactive or may antagonize true vitamin $\mathrm{B}_{12}$ (Dagnelie et al. 1991; Dagnelie, 1997).

Early studies of vitamin $B_{12}$ status in vegetarians have shown that, as would be expected, dietary intake and plasma concentrations are lower than those in meat-eaters (Armstrong et al. 1974; Sanders et al. 1978b). Clinical 
evidence of vitamin $\mathrm{B}_{12}$ deficiency has been reported in some vegans but is apparently uncommon (Antony, 2003). Recent research using more sensitive indicators of vitamin $\mathrm{B}_{12}$ status (plasma methylmalonic acid, homocysteine and holotranscobalamin II) has shown that substantial proportions of vegans and even of vegetarians have suboptimal vitamin $B_{12}$ status according to these criteria, both among affluent Western vegetarians and in other countries including India, China and Taiwan (Mann et al. 1999; Refsum et al. 2001; Hung et al. 2002; Kwok et al. 2002; Herrmann et al. 2003; Koebnick et al. 2004). Dietary vitamin $B_{12}$ deficiency is also now recognized to be a serious problem in non-vegetarian populations with a low intake of meat because of poverty (Stabler \& Allen, 2004).

Recent work shows that vegetarians must be careful to ensure that they do consume adequate amounts of vitamin B $_{12}$ (Herrmann \& Geisel, 2002; Antony, 2003; Stabler \& Allen, 2004). The current UK dietary reference values for vitamin $\mathrm{B}_{12}(1.5 \mu \mathrm{g} / \mathrm{d}$ in adults; Department of Health, 1991) were derived partly from studies of vegetarians and vegans that have suggested that intakes of vitamin $B_{12}$ of approximately $0.3 \mu \mathrm{g} / \mathrm{d}$ are sufficient to prevent anaemia and macrocytosis. However, intakes of $0.3 \mu \mathrm{g} / \mathrm{d}$ may be probably associated with moderate elevation in homocysteine that might be detrimental to health.

\section{Iron}

The Fe content of vegetarian diets is typically quite similar to that of non-vegetarian diets, but the bioavailability of the $\mathrm{Fe}$ is lower because of the absence of haem-Fe. Vegan diets are usually higher in $\mathrm{Fe}$ than lacto-vegetarian diets because dairy products are low in Fe. For example, in EPIC-Oxford estimated Fe intakes among 43582 women are $12 \cdot 6,12 \cdot 8,12 \cdot 6$ and $14 \cdot 1 \mathrm{mg} / \mathrm{d}$ for meat-eaters, fisheaters, lacto-vegetarians and vegans respectively (Davey et al. 2003). Studies of $\mathrm{Fe}$ status (for example, see Waldmann et al. 2004) have consistently shown that serum ferritin is lower in vegetarians than in non-vegetarians and that $\mathrm{Hb}$ levels are similar or slightly lower in vegetarians than in non-vegetarians. Low Fe status is not common in men, but is moderately common among premenopausal women throughout the world, and young female vegetarians need to ensure that their diet includes good sources of Fe with vitamin $\mathrm{C}$ to help absorption and that they take supplements if needed.

\section{Growth and development}

A well-planned vegetarian diet is considered to be adequate for all stages of the life cycle including infancy, childhood and adolescence (American Dietetic Association and Dietitians of Canada, 2003), but epidemiological data on growth and development in vegetarians are still sparse. Recent data on 390 lifelong vegetarians in EPIC-Oxford (Rosell et al. 2005a) show no significant differences in height in men or women, or in age at menarche in women, between lifelong vegetarians and those who became vegetarian at age $\geq 20$ years.

\section{Obesity}

Studies of Western vegetarians have consistently reported that vegetarians have a lower BMI than comparable non-vegetarians, with differences in mean BMI of about $1 \mathrm{~kg} / \mathrm{m}^{2}$ (Key et al. 1999b); the proportion of vegetarians who are obese is correspondingly lower than that among non-vegetarians (Key \& Davey, 1996). The reasons for this difference are not well understood, but may include differences in the composition of the diet such as a higher fibre intake and a lower protein intake (Spencer et al. 2003). Follow-up of body weight among 21966 individuals in EPIC-Oxford shows a mean body-weight increase of approximately $400 \mathrm{~g} / y e a r$ overall, with significantly lower weight gain in vegans, but not in vegetarians, than in meat-eaters (Rosell et al. 2005b).

Despite these consistently-observed differences in BMI between vegetarians and non-vegetarians, obesity is common among some populations that follow largely vegetarian diets, such as Indians living in the UK (Jebb et al. 2004) and in India (Shetty, 2002).

\section{CVD}

Plasma cholesterol

Studies have consistently reported that total plasma cholesterol is lower in vegetarians than in non-vegetarians, e.g. by $0.61 \mathrm{mmol} / \mathrm{l}$ in the Health Food Shoppers Study, $0.43 \mathrm{mmol} / \mathrm{l}$ in the Oxford Vegetarian Study and $0.39 \mathrm{mmol} / \mathrm{l}$ and $0.35 \mathrm{mmol} / \mathrm{l}$ in men and women respectively in EPIC-Oxford (Key et al. 1999b). The effect of a vegetarian diet on plasma cholesterol is dependent on the exact composition of the diet, particularly in relation to saturated and unsaturated fatty acids, and Jenkins et al. (2003) have shown that a vegetarian diet including a portfolio of cholesterol-lowering foods such as soyabean and nuts reduces serum LDL-cholesterol substantially more than a control vegetarian diet.

\section{Hypertension}

The main diet-related determinants of hypertension are high salt intake, obesity and excess alcohol consumption (Scientific Advisory Committee on Nutrition, 2003). Some early studies have suggested that vegetarians have a lower blood pressure than similar non-vegetarians, with differences of $2-10 \mathrm{mmHg}$ in systolic or diastolic pressure (Beilin et al. 1988). However, analyses of blood pressure among 11004 men and women in EPIC-Oxford indicate very little difference in blood pressure between vegetarians and meat-eaters $(\leq 1 \mathrm{mmHg})$; blood pressure was observed to be $2-3 \mathrm{mmHg}$ lower in vegans than in meat-eaters, largely associated with the lower BMI of the vegans (Appleby et al. 2002). In this study the very small differences in blood pressure between the dietary groups would not be expected to cause a detectable difference in rates of CVD.

\section{IHD}

Collaborative re-analysis of five prospective studies, each including a large proportion of vegetarians, has shown the 
mortality from IHD to be $24(95 \%$ CI 6,38$) \%$ lower in vegetarians than in non-vegetarians (Key et al. 1999b). Results published subsequently are similar; a death rate ratio of $0.75(95 \% \mathrm{CI} 0.4,1.37)$ in the first analysis of EPIC-Oxford (Key et al. 2003) and 0.70 (95\% CI 0.41, $1 \cdot 18)$ in the extended follow-up of the cohort in Germany (Chang-Claude et al. 2005). In a case-control study among Indians in Bangalore the risk for myocardial infarction in vegetarians compared with non-vegetarians has been reported to be $0 \cdot 81$ (95\% CI 0.46, 1.43; Pais et al. 1996).

Law et al. (1994) have estimated that a reduction in total serum cholesterol of $0.6 \mathrm{mmol} / 1$ would reduce mortality from IHD by $27 \%$; therefore, the observed differences in cholesterol between vegetarians and non-vegetarians of approximately $0.4 \mathrm{mmol} / \mathrm{l}$ would be expected to reduce mortality from IHD by approximately $20 \%$. The observed difference in mortality of about $24 \%$ is therefore of the magnitude that might be predicted from the difference in serum cholesterol. The lower BMI of vegetarians would also be expected to cause a small reduction in mortality from IHD.

\section{Stroke}

The main known risk factor for stroke is high blood pressure. The only data on stroke mortality in vegetarians comes from the five prospective studies, pooled analysis of which shows a death rate ratio for stroke in vegetarians compared with non-vegetarians of 0.93 (95\% CI 0.74 , 1.17; Key et al. 1999b).

\section{Cancer}

There are few data on cancer rates in vegetarians but some information is available, particularly for colo-rectal, breast and prostate cancer.

\section{Colo-rectal cancer}

The causes of colo-rectal cancer are not well understood but researchers agree that diet is important, and there is substantial, although not conclusive, evidence that diets high in red and processed meat are associated with a moderate increase in colo-rectal cancer risk (Key et al. 2004; Norat et al. 2005). As well as the absence of meat from their diet, some putative risk factors for colo-rectal cancer are more favourable in vegetarians than in nonvegetarians; for example, vegetarians have a lower proportion of secondary bile acids in their faeces (Reddy et al. 1998) and are less likely to have infrequent bowel movements (Sanjoaquin et al. 2004a). Studies of colorectal cancer in vegetarians have suggested that the incidence may be lower than in non-vegetarians (Fraser, 1999; Sanjoaquin et al. 2004b), but the pooled analysis of mortality among vegetarians and non-vegetarians in five cohorts shows no difference between the dietary groups (Key et al. 1999b; some of the cases in this analysis of mortality are the same individuals as in the studies of incidence of Fraser (1999) and Sanjoaquin et al. (2004b).

\section{Breast cancer}

Most of the epidemiology of breast cancer can be explained by hormonal factors, and the only definite dietary effects on risk are obesity in post-menopausal women and alcohol. Endogenous oestrogen levels are clearly associated with breast cancer risk in postmenopausal women (Key et al. 2002), and there is some evidence that high levels of insulin-like growth factor-I may also increase risk (Renehan et al. 2004). Although studies of hormone levels in vegetarians have shown that plasma oestrogen levels are not different from those of non-vegetarians (Thomas et al. 1999), they have shown that vegans have lower plasma levels of insulin-like growth factor-I than either meat-eaters or lacto-vegetarians (Allen et al. 2002). Vegetarians, and especially vegans, often consume substantial amounts of soyabeans or foods made from soyabeans; soya foods are rich in phyto-oestrogens, which have been hypothesized to reduce breast cancer risk but research on this topic has so far been inconclusive (Peeters et al. 2003).

Studies of breast cancer incidence or mortality have not demonstrated any difference between lacto-vegetarians and non-vegetarians (Mills et al. 1989a; Rao et al. 1994; Key et al. 1999b; Dos Santos Silva et al. 2002).

\section{Prostate cancer}

Hormones are thought to be important determinants of prostate cancer risk, but understanding of these relationships is still poor. There is some evidence that high levels of active androgens and of insulin-like growth factor-I may increase prostate cancer risk (Eaton et al. 1999; Renehan et al. 2004). No differences in androgens have been found between vegetarians and non-vegetarians but, as in women, vegan men have lower plasma levels of insulin-like growth factor-I than either meat-eaters or lacto-vegetarians (Allen et al. 2000).

Studies of prostate cancer incidence or mortality have not demonstrated any difference between lacto-vegetarians and non-vegetarians (Mills et al. 1989b; Key et al. 1999b).

\section{Bone health}

The bone health of vegetarians has been a topic of interest for many years but few data are available. Ca intake in lacto-vegetarians is similar to that in non-vegetarians, whereas vegans usually have a substantially lower $\mathrm{Ca}$ intake unless they consume a lot of Ca-rich plant foods such as dark-green vegetables. It has been suggested that the absence of meat might be beneficial for bone health because of a reduced 'acid load', but whether this factor is important is controversial and overall it is not clear whether the bone health of vegetarians is better or worse than that of comparable non-vegetarians (New, 2004). Early results from EPIC-Oxford show no difference in fracture rates between vegetarians and non-vegetarians, but do show the importance of adequate $\mathrm{Ca}$ intake in reducing fracture risk (TJ Key, PN Appleby, EA Spencer, AW Roddam and NE Allen, unpublished results). 


\section{Vegetarian athletes}

The question of whether vegetarianism is associated with beneficial or detrimental effects on athletic performance has been investigated in some observational studies and a few small trials (Nieman, 1999; Barr \& Rideout, 2004). In general, there is little evidence that athletic performance differs much between vegetarians and non-vegetarians, as long as the diet is nutritionally adequate, but more data are needed. Particular care needs to be taken to ensure adequate $\mathrm{Fe}$ status, and there is some evidence that the lower muscle creatine concentration in vegetarians may reduce supramaximal exercise performance (Barr \& Rideout, 2004).

\section{Total mortality}

Total mortality appears to be similar in vegetarians and comparable non-vegetarians; in the pooled analysis of five prospective studies the death rate ratio in vegetarians compared with non-vegetarians is $0 \cdot 95$ (95\% CI 0.82, 1.11; Key et al. 1999b), and a subsequent analysis in EPICOxford shows a death rate ratio of 1.05 (95\% CI 0.86, 1.27; Key et al. 2003). Calculation of the standardized mortality ratio in the three UK cohorts shows that mortality in the vegetarians is much lower than that in the general population of England and Wales, with standardized mortality ratios (mortality rates expressed as a proportion of the national mortality rates, allowing for the effect of age; \%) of 59 (95\% CI 55, 63), 51 (95\% CI 47, 56) and 40 (95\% CI 35, 45) in the Health Food Shoppers study, the Oxford Vegetarian Study, and EPIC-Oxford respectively (Key et al. 2003). Low standardized mortality ratios are normally seen in cohort studies of volunteers, but these low values for vegetarians do demonstrate that in general terms their health is good.

\section{Conclusions}

Although there are now many publications with data for vegetarians, there are not yet enough data from large studies to allow more than broad conclusions about the health effects of vegetarian diets. In Western countries the health of vegetarians appears to be good compared with national averages and similar to that of non-vegetarians with a comparable background and lifestyle. This outcome is partly because vegetarians tend to be more health conscious than average (for example, by avoiding smoking) and partly because vegetarians have reasonably healthy diets in relation to factors such as fat composition. Vegetarians have consistently been observed to have a lower mean BMI than comparable non-vegetarians. In the available studies vegetarians have been shown to have lower mortality from IHD than comparable non-vegetarians, probably because they have lower blood cholesterol. No clear differences have been shown for other major causes of death such as stroke and cancers of the colo-rectum, breast and prostate. The relatively low blood levels of insulin-like growth factor-I observed in vegans might cause a reduction in risk for cancers of the breast and prostate, but there are no data on the risk for these cancers in vegans; the only data on cancer risk are for vegetarians, mostly lacto-vegetarians, who do not have reduced levels of insulin-like growth factor-I. Vegetarians have low levels of long-chain $n-3$ fatty acids and often have low levels of vitamin $B_{12}$ and raised levels of homocysteine; more research on the health effects of these differences is needed. Overall, the health of vegetarians appears to be good, but as with all dietary patterns care is needed to ensure that the diet is as nutritious and well-balanced as possible according to current understanding.

\section{References}

Allen NE, Appleby PN, Davey GK, Kaaks R, Rinaldi S \& Key TJ (2002) The associations of diet with serum insulin-like growth factor I and its main binding proteins in 292 women meat-eaters, vegetarians, and vegans. Cancer Epidemiology, Biomarkers \& Prevention 11, 1441-1448.

Allen NE, Appleby PN, Davey GK \& Key TJ (2000) Hormones and diet: low insulin-like growth factor-I but normal bioavailable androgens in vegan men. British Journal of Cancer 83, 95-97.

American Dietetic Association and Dietitians of Canada (2003) Position of the American Dietetic Association and Dietitians of Canada: Vegetarian diets. Journal of the American Dietetic Association 103, 748-765.

Antony AC (2003) Vegetarianism and vitamin B-12 (cobalamin) deficiency. American Journal of Clinical Nutrition 78, 3-6.

Appleby PN, Davey GK \& Key TJ (2002) Hypertension and blood pressure among meat eaters, fish eaters, vegetarians and vegans in EPIC-Oxford. Public Health Nutrition 5, 645-654.

Armstrong BK, Davis RE, Nicol DJ, van Merwyk AJ \& Larnwood CJ (1974) Hematological, vitamin B-12 and folate studies on seventh-day Adventist vegetarians. American Journal of Clinical Nutrition 27, 712-718.

Barr SI \& Rideout CA (2004) Nutritional considerations for vegetarian athletes. Nutrition 20, 696-703.

Beilin LJ, Rouse IL, Armstrong BK, Margetts BM \& Vandongen R (1988) Vegetarian diet and blood pressure levels: incidental or causal association? American Journal of Clinical Nutrition 48, 806-810.

Chang-Claude J, Hermann S, Eilber U \& Steindorf K (2005) Lifestyle determinants and mortality in German vegetarians and health-conscious persons: results of a 21-year follow-up. Cancer Epidemiology, Biomarkers \& Prevention 14, 963-968.

Dagnelie PC (1997) Some algae are potentially adequate sources of vitamin B-12 for vegans. Journal of Nutrition 127, 379.

Dagnelie PC, van Staveren WA \& van den Berg H (1991) Vitamin B-12 from algae appears not to be bioavailable. American Journal of Clinical Nutrition 53, 695-697.

Davey GK, Spencer EA, Appleby PN, Allen NE, Knox KH \& Key TJ (2003) EPIC-Oxford: lifestyle characteristics and nutrient intakes in a cohort of 33883 meat-eaters and 31546 non meat-eaters in the UK. Public Health Nutrition 6, 259-269.

Davis BC \& Kris-Etherton PM (2003) Achieving optimal essential fatty acid status in vegetarians: current knowledge and practical implications. American Journal of Clinical Nutrition 78, Suppl., 640S-646S.

Department of Health (1991) Dietary Reference Values for Food Energy and Nutrients for the United Kingdom. Report on Health and Social Subjects no. 41. London: H. M. Stationery Office. 
Dos Santos Silva I, Mangtani P, McCormack V, Bhakta D, Sevak L \& McMichael AJ (2002) Lifelong vegetarianism and risk of breast cancer: a population-based case-control study among South Asian migrant women living in England. International Journal of Cancer 99, 238-244.

Eaton NE, Reeves GK, Appleby PN \& Key TJ (1999) Endogenous sex hormones and prostate cancer: a quantitative review of prospective studies. British Journal of Cancer 80, 930-934.

Fraser GE (1999) Associations between diet and cancer, ischemic heart disease, and all-cause mortality in non-Hispanic white California Seventh-day Adventists. American Journal of Clinical Nutrition 70, Suppl., 532S-538S.

Henderson L, Gregory J \& Swan G (2002) National Diet and Nutrition Survey: Adults Aged 19 to 64 Years. vol. 1: Types and Quantities of Foods Consumed. London: The Stationery Office.

Herbert V (1988) Vitamin B-12: plant sources, requirements, and assay. American Journal of Clinical Nutrition 48, Suppl., 852-858.

Herrmann W \& Geisel J (2002) Vegetarian lifestyle and monitoring of vitamin B-12 status. Clinica Chimica Acta 326, $47-59$.

Herrmann W, Schorr H, Obeid R \& Geisel J (2003) Vitamin B-12 status, particularly holotranscobalamin II and methylmalonic acid concentrations, and hyperhomocysteinemia in vegetarians. American Journal of Clinical Nutrition 78, 131-136.

Hung CJ, Huang PC, Lu SC, Li YH, Huang HB, Lin BF, Chang SJ \& Chou HF (2002) Plasma homocysteine levels in Taiwanese vegetarians are higher than those of omnivores. Journal of Nutrition 132, 152-158.

International Vegetarian Union (2005) 37th IVU World Vegetarian Congress Goa, India, September 10-16, 2006. Healthy Lifestyle - Vegetarian Way! http://www.ivu.org/congress/ 2006/whyindia.html (accessed June 2005).

Jebb SA, Rennie KL \& Cole TJ (2004) Prevalence of overweight and obesity among young people in Great Britain. Public Health Nutrition 7, 461-465.

Jenkins DJ, Kendall CW, Marchie A, Faulkner DA, Wong JM, de Souza R et al. (2003) Effects of a dietary portfolio of cholesterol-lowering foods vs lovastatin on serum lipids and C-reactive protein. Journal of the American Medical Association 290, 502-510.

Key T, Appleby P, Barnes I \& Reeves G (2002) Endogenous sex hormones and breast cancer in postmenopausal women: reanalysis of nine prospective studies. Journal of the National Cancer Institute 94, 606-616.

Key T \& Davey G (1996) Prevalence of obesity is low in people who do not eat meat. British Medical Journal 313, 816-817.

Key TJ, Appleby PN, Davey GK, Allen NE, Spencer EA \& Travis RC (2003) Mortality in British vegetarians: review and preliminary results from EPIC-Oxford. American Journal of Clinical Nutrition 78, Suppl., 533S-538S.

Key TJ, Davey GK \& Appleby PN (1999a) Health benefits of a vegetarian diet. Proceedings of the Nutrition Society 58, 271-275.

Key TJ, Fraser GE, Thorogood M, Appleby PN, Beral V, Reeves G et al. (1999b) Mortality in vegetarians and nonvegetarians: detailed findings from a collaborative analysis of 5 prospective studies. American Journal of Clinical Nutrition 70, Suppl., 516S-524S.

Key TJ, Schatzkin A, Willett WC, Allen NE, Spencer EA \& Travis RC (2004) Diet, nutrition and the prevention of cancer. Public Health Nutrition 7, 187-200.

Koebnick C, Hoffmann I, Dagnelie PC, Heins UA, Wickramasinghe SN, Ratnayaka ID, Gruendel S, Lindemans J \& Leitzmann C (2004) Long-term ovo-lacto vegetarian diet impairs vitamin B-12 status in pregnant women. Journal of Nutrition 134, 3319-3326.

Kwok T, Cheng G, Woo J, Lai WK \& Pang CP (2002) Independent effect of vitamin B12 deficiency on hematological status in older Chinese vegetarian women. American Journal of Hematology 70, 186-190.

Law MR, Wald NJ, Wu T, Hackshaw A \& Bailey A (1994) Systematic underestimation of association between serum cholesterol concentration and ischaemic heart disease in observational studies: data from the BUPA study. British Medical Journal 308, 363-366.

Mann NJ, Li D, Sinclair AJ, Dudman NP, Guo XW, Elsworth GR, Wilson AK \& Kelly FD (1999) The effect of diet on plasma homocysteine concentrations in healthy male subjects. European Journal of Clinical Nutrition 53, 895-899.

Mezzano D, Kosiel K, Martinez C, Cuevas A, Panes O, Aranda E, Strobel P, Perez DD, Pereira J, Rozowski J \& Leighton F (2000) Cardiovascular risk factors in vegetarians. Normalization of hyperhomocysteinemia with vitamin $\mathrm{B}(12)$ and reduction of platelet aggregation with n-3 fatty acids. Thrombosis Research 100, 153-160.

Mills PK, Beeson WL, Phillips RL \& Fraser GE (1989a) Dietary habits and breast cancer incidence among Seventh-day Adventists. Cancer 64, 582-590.

Mills PK, Beeson WL, Phillips RL \& Fraser GE (1989b) Cohort study of diet, lifestyle, and prostate cancer in Adventist men. Cancer 64, 598-604.

New SA (2004) Do vegetarians have a normal bone mass? Osteoporosis International 15, 679-688.

Nieman DC (1999) Physical fitness and vegetarian diets: is there a relation? American Journal of Clinical Nutrition 70, Suppl., 570S-575S.

Norat T, Bingham S, Ferrari P, Slimani N, Jenab M, Mazuir M et al. (2005) Meat, fish, and colorectal cancer risk: the European Prospective Investigation into Cancer and Nutrition. Journal of the National Cancer Institute 97, 906916.

Pais P, Pogue J, Gerstein H, Zachariah E, Savitha D, Jayprakash S, Nayak PR \& Yusuf S (1996) Risk factors for acute myocardial infarction in Indians: a case-control study. Lancet 348, 358-363.

Peeters PH, Keinan-Boker L, van der Schouw YT \& Grobbee DB (2003) Phytoestrogens and breast cancer risk. Review of the epidemiological evidence. Breast Cancer Research and Treatment 77, 171-183.

Rao DN, Ganesh B \& Desai PB (1994) Role of reproductive factors in breast cancer in a low-risk area: a case-control study. British Journal of Cancer 70, 129-132.

Reddy S, Sanders TA, Owen RW \& Thompson MH (1998) Faecal pH, bile acid and sterol concentrations in premenopausal Indian and white vegetarians compared with white omnivores. British Journal of Nutrition 79, 495-500.

Refsum H, Yajnik CS, Gadkari M, Schneede J, Vollset SE, Orning L, Guttormsen AB, Joglekar A, Sayyad MG, Ulvik A \& Ueland PM (2001) Hyperhomocysteinemia and elevated methylmalonic acid indicate a high prevalence of cobalamin deficiency in Asian Indians. American Journal of Clinical Nutrition 74, 233-241.

Renehan AG, Zwahlen M, Minder C, O'Dwyer ST, Shalet SM \& Egger M (2004) Insulin-like growth factor (IGF)-I, IGF binding protein-3, and cancer risk: systematic review and meta-regression analysis. Lancet 363, 346-353.

Rosell M, Appleby P \& Key T (2005a) Height, age at menarche, body weight, and body mass index in life-long vegetarians. Public Health Nutrition 8, 870-878.

Rosell M, Appleby P, Spencer E \& Key T (2005b) Weight gain over 5 years in 21966 meat-eating, fish-eating, vegetarian and 
vegan men and women in EPIC-Oxford. International Journal of Obesity (In the Press).

Rosell MS, Lloyd-Wright Z, Appleby PN, Sanders TAB, Allen NE \& Key TJ (2005c) Long-chain n-3 polyunsaturated fatty acids in plasma in British meat-eating, vegetarian, and vegan men. American Journal of Clinical Nutrition 82, 327334.

Sanders TA (1999a) The nutritional adequacy of plant-based diets. Proceedings of the Nutrition Society 58, 265-269.

Sanders TA (1999b) Essential fatty acid requirements of vegetarians in pregnancy, lactation, and infancy. American Journal of Clinical Nutrition 70, Suppl., 555S-559S.

Sanders TA, Ellis FR \& Dickerson JW (1978a) Studies of vegans: the fatty acid composition of plasma choline phosphoglycerides, erythrocytes, adipose tissue, and breast milk, and some indicators of susceptibility to ischemic heart disease in vegans and omnivore controls. American Journal of Clinical Nutrition 31, 805-813.

Sanders TA, Ellis FR \& Dickerson JW (1978b) Haematological studies on vegans. British Journal of Nutrition 40, 9-15.

Sanjoaquin MA, Appleby PN, Spencer EA \& Key TJ (2004a) Nutrition and lifestyle in relation to bowel movement frequency: a cross-sectional study of 20630 men and women in EPIC-Oxford. Public Health Nutrition 7, 77-83.

Sanjoaquin MA, Appleby PN, Thorogood M, Mann JI \& Key TJ (2004b) Nutrition, lifestyle and colorectal cancer incidence: a prospective investigation of 10998 vegetarians and nonvegetarians in the United Kingdom. British Journal of Cancer 90, $118-121$.
Scientific Advisory Committee on Nutrition (2003) Salt and Health. London: The Stationery Office.

Shetty PS (2002) Nutrition transition in India. Public Health Nutrition 5, 175-182.

Spencer EA, Appleby PN, Davey GK \& Key TJ (2003) Diet and body mass index in 38000 EPIC-Oxford meat-eaters, fish-eaters, vegetarians and vegans. International Journal of Obesity and Related Metabolic Disorders 27, 728-734.

Stabler SP \& Allen RH (2004) Vitamin B12 deficiency as a worldwide problem. Annual Review of Nutrition 24, 299-326.

Steinfeld H (2004) The livestock revolution - a global veterinary mission. Veterinary Parasitology 125, 19-41.

Thomas HV, Davey GK \& Key TJ (1999) Oestradiol and sex hormone-binding globulin in premenopausal and postmenopausal meat-eaters, vegetarians and vegans. British Journal of Cancer 80, 1470-1475.

Waldmann A, Koschizke JW, Leitzmann C \& Hahn A (2004) Dietary iron intake and iron status of German female vegans: results of the German vegan study. Annals of Nutrition and Metabolism 48, 103-108.

Willett W (1999) Lessons from dietary studies in Adventists and questions for the future. American Journal of Clinical Nutrition 78, Suppl., 539S-543S.

Williams CM \& Burdge G (2006) Long-chain $n$-3 PUFA: plant v. marine sources. Proceedings of the Nutrition Society 65, 42-50.

World Health Organization (2003) Diet, Nutrition and the Prevention of Chronic Diseases. WHO Technical Report Series no. 916. Geneva: WHO. 